\title{
Analysis of the factors influencing the survival time of patients with sarcomatoid renal cell carcinoma
}

\author{
YU-SHENG WANG, WEI-BING SHUANG, KE-QIANG YIN, \\ XU-NAN TONG, MAN-CHENG XIA and HAO-SEN YANG \\ Department of Urology, The First Hospital of Shanxi Medical University, Yingze, Shanxi 030001, P.R. China
}

Received January 31, 2019; Accepted May 13, 2019

DOI: $10.3892 / \operatorname{mco} .2019 .1900$

\begin{abstract}
The aim of the present study was to identify the factors influencing the survival time of patients with sarcomatoid renal cell carcinoma (SRCC). Between January 2000 and September 2017, a total of 21 patients were enrolled, all of whom were diagnosed with SRCC. In total, eight prognostic factors were analyzed using the Kaplan-Meier estimator, a log-rank test and Cox's proportional hazards model. The log-rank test results revealed that there was a significant association between the proportion of sarcoma elements and survival time of patients with SRCC $(\mathrm{P}<0.05)$. In addition, there was a significant association between post-operative drug treatment and SRCC survival time $(\mathrm{P}<0.05)$. The results of the Kaplan-Meier estimate demonstrated that the survival curve of post-operative drug treatment was significantly greater compared with the survival curve of patients who did not undergo drug treatment $(\mathrm{P}<0.05)$. The survival curve of patients with a proportion of sarcoma elements $<50 \%$ was significantly greater compared with the survival curve of patients with a proportion of sarcoma elements $\geq 50 \%(\mathrm{P}<0.05)$. Furthermore, the Cox's proportional hazards model revealed that the mortality risk in post-operative patients without drug treatment was 5.822 times greater compared with that of patients with drug treatment $(\mathrm{P}<0.05)$. Mortality risk in patients with a proportion of sarcoma elements $\geq 50 \%$ was 4.682 times higher compared with that of patients with sarcoma elements $<50 \%$ $(\mathrm{P}<0.05)$. Finally, post-operative drug therapy was revealed to be a protective factor which significantly affected the survival time of patients with SRCC [risk ratio $(\mathrm{RR})=0.172$ ], in addition to the proportion of sarcoma elements $\geq 50 \%$ ( $R R=4.682$ ). In conclusion, drug therapy should be promoted upon patient
\end{abstract}

Correspondence to: Dr Wei-Bing Shuang, Department of Urology, The First Hospital of Shanxi Medical University, 85 Jiefang Road, Yingze, Shanxi 030001, P.R. China

E-mail: shuangweibing@126.com

Key words: sarcomatoid renal cell carcinoma, survival time, survival analysis, Cox proportional hazards model, Kaplan-Meier estimate, log-rank test diagnosis with SRCC and attention should be given to the proportion of sarcomatoid components.

\section{Introduction}

Renal cell carcinoma (RCC) is a common tumor, accounting for $21.82 \%$ of urinary tumors, second only to bladder and prostate cancer (1). In China, the incidence of renal cancer increases every year (2). There are several pathological types of renal cell carcinoma which include: Clear cell carcinoma, papillary renal cell carcinoma, chromophobe cell carcinoma, collecting ductal carcinoma and medullary carcinoma (2). Approximately $30 \%$ of patients with renal cell carcinoma exhibit distant metastasis at the time of initial diagnosis, and $\sim 50 \%$ of patients with localized renal cell carcinoma exhibit distant metastasis following surgery (3). Sarcomatoid renal cell carcinoma (SRCC) is a rare type of renal cell carcinoma, with a high malignancy and a poor prognosis (4). SRCC accounts for $\sim 5-7 \%$ of all RCC cases $(5,6)$. The incidence of SRCC is increased in males compared with females, particularly in the unilateral and right kidney (4). The median survival time of patients is 6-12 months amongst those aged 31-81 (median age, 60 years) (4). Histologically, SRCC is composed of epithelial (cancerous) and mesenchymal (sarcomatoid) components, which is in difference to renal sarcoma $(7,8)$. SRCC is a more aggressive and advanced form of kidney cancer, which has a shorter overall survival (9). It has therefore been the subject of many studies.

At present, SRCC treatment includes surgery, chemotherapy and radiotherapy, in addition to targeted biological and cytokine therapies (4). Surgery alone is often an inadequate measure to cure patients (10-12). Furthermore, SRCC does not respond well to cytotoxic chemotherapy, cytokines and targeted therapies $(9,13)$. A higher percentage of sarcomatoid features are also associated with a poorer survival $(14,15)$.

Considering the multitude of factors that influence the survival time of patients with SRCC, in the present study a multivariate Cox's proportional hazards regression model was used to analyze the factors affecting the survival time of patients with SRCC.

\section{Materials and methods}

Patients. The present study was ethically approved by the ethical review board of The First Hosptial of Shanxi Medical 
University (approval no. 2018-K006). A retrospective review was performed to identify patients with SRCC whose diagnoses were confirmed using pathology between January 2000 and September 2017 at The First Hospital of Shanxi Medical University. In total, 21 patients were included (13 males; 8 females; mean age, 57 years; age range, 30-77 years). Four cases were treated at The First Hosptial of Shanxi Medical University; the other 17 cases were retrieved from a reference search. Clinical data were collected, including sex, age, maximum tumor size, the proportion of sarcoma elements, lymph node metastasis, distant metastasis, surgery and drug therapy. The proportion of sarcoma elements was defined as the proportion of sarcoma elements to the whole tumor observed under a microscope.

Data analysis. All patient data were analyzed using the Kaplan-Meier estimate and log-rank test for univariate analysis. In addition, survival curves between the two groups were compared using the log-rank method. A Cox's proportional hazard model was used for multivariate analysis. Data were assigned numbers, which are presented in Table I. SPSS version 20 (IBM Corp, Armonk, NY, USA). P $<0.05$ was considered to indicate a statistically significant difference.

\section{Results}

Clinical data. In total, 14 patients had a proportion of sarcoma elements $>50 \%$ in their tumor samples, and seven patients with $<50 \%$. Nine patients received drug treatment, whereas 12 patients did not. Full characteristics of the patient population are presented in Table II (16-26).

Univariate analysis. There was a significant negative association between the proportion of sarcoma elements and survival time $(\mathrm{P}<0.02)$. In addition, there was a significant positive association between drug treatment and survival time $(\mathrm{P}<0.02$; Table III). The Kaplan-Meier curves revealed that the post-operative non-drug treatment group had a significantly shorter survival time compared with the drug treatment group $(\mathrm{P}<0.05$; Fig. 1A). Patients with a proportion of sarcoma components $\geq 50 \%$ exhibited a significantly shorter survival time compared with the $<50 \%$ group $(\mathrm{P}<0.05$; Fig. 1B).

Multivariate analyses. The multivariate Cox's proportional hazard model revealed that drug treatment [risk ratio (RR), 0.171; 95\% confidence interval (CI), 0.049-0.591; $\mathrm{P}=0.005$ ] was a significant protective factor in survival time. Mortality risk in the post-operative non-drug therapy patients following surgery was 5.822 times greater compared with that of the post-operative drug therapy group. It also revealed that a $\geq 50 \%$ proportion of sarcoma elements (RR, $4.682 ; 95 \% \mathrm{CI}$, 1.345-16.299; $\mathrm{P}=0.015$ ) was a significant risk factor for survival time. Mortality risk in the $\geq 50 \%$ group was 4.682 times higher compared with those in the $<50 \%$ group (Table IV).

\section{Discussion}

Identifying the factors that impact the biological behavior of SRCC is essential for understanding the natural course of the disease in patients. Drug treatment induces adverse effects
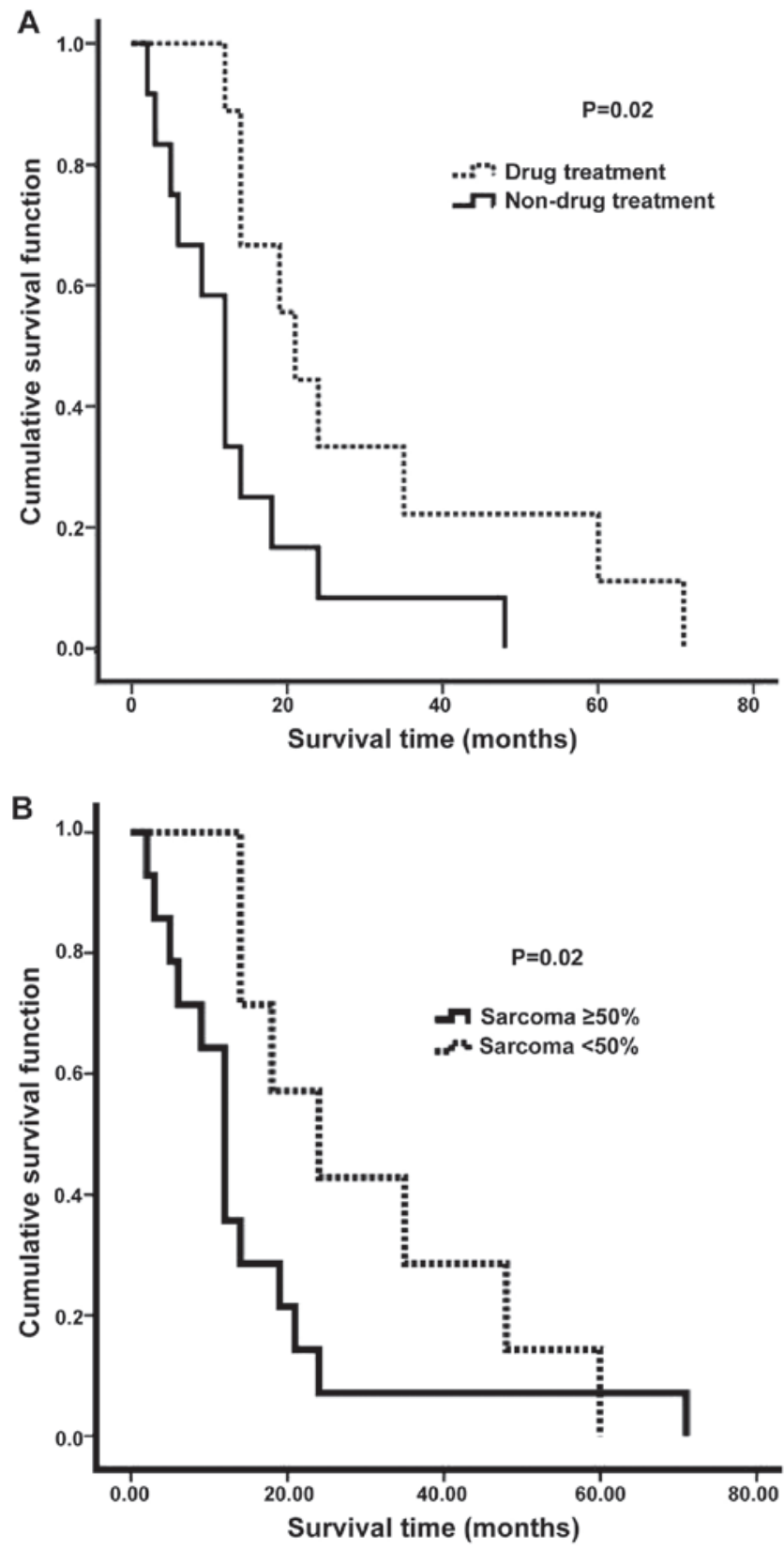

Figure 1. Survival curves of patients with sarcomatoid renal cell carcinoma. (A) Survival time in patients who had undergone drug treatment compared with those who had not. (B) Survival time in patients with a proportion of sarcoma elements $\geq 50 \%$ compared with those with a proportion of sarcoma elements $<50 \%$.

in almost every patient (27). Therefore, it is necessary to avoid treating patients who will not ultimately benefit from drug therapy. It is evident that the clinical behavior of SRCC results from complex interactions between multiple prognostic factors (27). The reported effects of chemotherapy and immunotherapy on SRCC differentiation are contradictory (27). Therefore, determining the prognostic factors of survival may be helpful in selecting patients for drug treatment.

It was hypothesized that drug treatment would have a beneficial effect on survival time. There are certain rationales for administering drug treatment for SRCC. Firstly, improved survival time was revealed in patients receiving high-dose interleukin-2 (IL-2) therapy, compared with patients treated 
Table I. Factors and assignments of sarcomatoid renal cell carcinoma.

\begin{tabular}{lcc}
\hline Factors & Variable name & Assignments \\
\hline Age & $\mathrm{X} 1$ & (year) \\
Sex & $\mathrm{X} 2$ & Female, $0 ;$ male, 1 \\
Sarcoma elements & $\mathrm{X} 3$ & $<50 \%, 0 ; \geq 50 \%, 1$ \\
Lymph node metastasis & $\mathrm{X} 4$ & No, $0 ;$ Yes, 1 \\
Distant metastasis & $\mathrm{X} 5$ & No, $0 ;$ Yes, 1 \\
Maximum diameter of the tumor & $\mathrm{X} 6$ & $(\mathrm{~cm})$ \\
Treatment method & $\mathrm{X} 7$ & Conservative, $0 ;$ surgery, 1 \\
Drug treatment & $\mathrm{X} 8$ & No, $0 ;$ Yes, 1 \\
Survival time & $\mathrm{t}$ & (months) \\
Survival outcome & $\mathrm{Y}$ & Censored, $0 ;$ death, 1
\end{tabular}

Table II. Characteristics of the patient population.

\begin{tabular}{|c|c|c|c|c|c|c|c|c|c|}
\hline Patient & Sex & $\begin{array}{c}\text { Age } \\
\text { (years) }\end{array}$ & $\begin{array}{l}\text { Maximum } \\
\text { tumor size }\end{array}$ & $\begin{array}{l}\text { Sarcoma } \\
\geq 50 \%\end{array}$ & $\begin{array}{l}\text { Lymph node } \\
\text { metastasis }\end{array}$ & $\begin{array}{c}\text { Distant } \\
\text { metastasis }\end{array}$ & Surgery & $\begin{array}{l}\text { Drug } \\
\text { treatment }\end{array}$ & $\begin{array}{c}\text { Survival } \\
\text { time (months) }\end{array}$ \\
\hline 1 & Male & 65 & 9 & Yes & No & Yes & Yes & No & 2 \\
\hline 2 & Male & 53 & 5.3 & Yes & Yes & Yes & Yes & No & 3 \\
\hline 3 & Male & 56 & 6 & No & Yes & No & Yes & No & 48 \\
\hline 4 & Male & 61 & 8 & No & Yes & Yes & Yes & No & 14 \\
\hline 5 & Male & 44 & 4.2 & Yes & No & Yes & Yes & Yes & 21 \\
\hline 6 & Female & 30 & 8.2 & Yes & Yes & Yes & No & No & 6 \\
\hline 7 & Female & 47 & 5 & No & No & No & Yes & No & 24 \\
\hline 8 & Male & 70 & 6.5 & Yes & No & Yes & Yes & No & 5 \\
\hline 9 & Male & 35 & 19 & Yes & Yes & Yes & Yes & Yes & 14 \\
\hline 10 & Male & 43 & 6 & Yes & No & No & Yes & No & 12 \\
\hline 11 & Male & 40 & 10 & Yes & No & No & Yes & No & 12 \\
\hline 12 & Female & 62 & 13 & Yes & Yes & Yes & Yes & Yes & 71 \\
\hline 13 & Male & 47 & 6 & Yes & No & No & Yes & No & 12 \\
\hline 14 & Male & 55 & 9 & No & No & Yes & Yes & Yes & 35 \\
\hline 15 & Male & 59 & 2.5 & Yes & No & Yes & Yes & Yes & 19 \\
\hline 16 & Female & 77 & 7 & Yes & Yes & No & Yes & Yes & 24 \\
\hline 17 & Female & 66 & 7 & Yes & No & No & Yes & No & 9 \\
\hline 18 & Female & 68 & 8 & No & Yes & Yes & Yes & Yes & 60 \\
\hline 19 & Male & 30 & 12 & No & No & No & No & Yes & 14 \\
\hline 20 & Female & 77 & 7 & Yes & Yes & Yes & Yes & Yes & 12 \\
\hline 21 & Female & 64 & 5.8 & No & No & No & Yes & No & 18 \\
\hline
\end{tabular}

with surgery alone or any other form of immunotherapy. The relative risk of mortality is 10.4 times higher in patients not receiving high-dose IL-2 therapy (28). Furthermore, surgical resection and high-dose IL-2-based immunotherapy may serve a function in the successful treatment of SRCC (28). Another report suggested that treatment with interferon- $\alpha$, compared with vinblastine or medroxyprogesterone, achieves a small improvement in survival time (29). Secondly, a recent study has revealed that the use of multiple targeted tyrosine kinase inhibitors, including sorafenib and sulinitinib, have produced a positive effect on patient survival time (30). Thirdly, chemotherapy with doxorubicin and gemcitabine may reverse clinical deterioration in certain patients, and cause the stabilization or regression of metastases (31). In addition, the combination of doxorubicin and gemcitabine has antitumor activity in patients with SRCC (11). However, in the present study, a significant beneficial effect of drug treatment on survival time was observed compared with the non-drug treatment group $(\mathrm{P}<0.05)$. The survival time of patients with postoperative drug treatment was 21 months, which was significantly higher compared with 12 months in the postoperative non-drug treatment group (Table III; $\mathrm{P}<0.05$ ). Drug treatment was much more commonly administered in Japan compared with China, consequently resulting in a longer survival time in Japan (26). 
Table III. Univariate analyses of factors affecting cancer-specific survival time.

\begin{tabular}{|c|c|c|c|c|}
\hline Factors & Cases & Median survival (months) & 1 -year survival rate $(\%)$ & P-value \\
\hline Age (years) & & & & 0.551 \\
\hline$<60$ & 12 & 14 & 83.3 & \\
\hline$\geq 60$ & 9 & 14 & 66.7 & \\
\hline Sex & & & & 0.148 \\
\hline Female & 8 & 14 & 75 & \\
\hline Male & 13 & 18 & 76.9 & \\
\hline Maximum tumor diameter $(\mathrm{cm})$ & & & & 0.565 \\
\hline$<7$ & 9 & 18 & 77.8 & \\
\hline$\geq 7$ & 12 & 14 & 75 & \\
\hline Sarcoma components (\%) & & & & $0.02^{\mathrm{a}}$ \\
\hline$<50$ & 7 & 12 & 100 & \\
\hline$\geq 50$ & 14 & 24 & 64.2 & \\
\hline Surgery & & & & 0.25 \\
\hline Yes & 19 & 14 & 78.9 & \\
\hline No & 2 & 6 & 50 & \\
\hline Drug treatment & & & & $0.02^{\mathrm{a}}$ \\
\hline Yes & 9 & 21 & 66.7 & \\
\hline No & 12 & 12 & 58.3 & \\
\hline Lymph node metastasis & & & & 0.12 \\
\hline Yes & 9 & 14 & 77.8 & \\
\hline No & 12 & 12 & 75 & \\
\hline Distant metastasis & & & & 0.61 \\
\hline Yes & 11 & 14 & 72.7 & \\
\hline No & 10 & 12 & 60 & \\
\hline
\end{tabular}

${ }^{\mathrm{a}} \mathrm{P}<0.05$.

Table IV. Analytical results by Cox's proportional hazard model.

\begin{tabular}{lcccccc}
\hline Factors & $\mathrm{bj}$ & $\mathrm{S}_{\mathrm{bj}}$ & Wald value & P-value & Exp (B) & 95\% confidence interval \\
\hline Sarcoma components & 1.544 & 0.636 & 5.885 & 0.015 & 4.682 & $(1.345,16.299)$ \\
Chemotherapy/Biological drug therapy & -1.768 & 0.634 & 7.786 & 0.005 & 0.171 & $(0.049,0.591)$ \\
\hline
\end{tabular}

It was confirmed the survival rate of patients with $\geq 50 \%$ sarcoma elements was worse compared with the $<50 \%$ group. This is consistent with other reports demonstrating that sarcomatoid architecture predicts poor survival $(32,33)$. The mean survival time of the patients in the $\geq 50 \%$ group was only 14 months, whereas those in the $<50 \%$ group had an mean survival time of 27 months, in other words that the higher the proportion of the sarcoma elements, the worse the prognosis of the patients (34). Numerous studies have demonstrated that sarcomatoid differentiation is associated with a poor prognosis (30,35-38). Patients with sarcomatoid differentiation have more aggressive tumor characteristics compared with those without sarcomatoid differentiation. Furthermore, it has been reported that sarcomatoid differentiation is an independent prognostic predictor of overall survival time (26).
Furthermore, the 2-year survival rate of patients in the $\geq 50 \%$ group was $7.1 \%$, whereas the survival rate for the $<50 \%$ group was $42 \%$. In conclusion, the higher the proportion of sarcoma elements, the worse the prognosis and the shorter the survival time.

The present study has a number of limitations. The number of studied SRCC cases was relatively small, due to the limited cases allotted. It was not possible to further analyze the types of drug treatment, so univariate and multivariate analyses could only be performed from the perspective of whether drug treatment was or was not used.

Analyzing the prognostic factors of survival for patients with SRCC would be valuable in guiding treatment. In the present study, the multivariate analysis of SRCC survival revealed that drug treatment was a protective factor that 
affected survival time ( $R R=0.172)$. Additionally, the proportion of sarcoma elements $\geq 50 \%$ was a risk factor that affected survival time $(\mathrm{RR}=4.682)$. Therefore, when a patient is diagnosed with SRCC, drug therapy may extend the patient's survival time to a certain extent. In addition, judging the proportion of sarcomatoid components may provide a reference to judge a patient's condition. However, SRCC is rare in clinical practice and the number of cases is limited. The present study has certain limitations and further cases will be collected for further analysis.

In the present study, the multivariate analysis of the survival time with SRCC revealed that postoperative drug treatment is a protective factor that affects survival time $(R R=0.172)$. The proportion of sarcoma elements $\geq 50 \%$ is a risk factor that affects survival time $(\mathrm{RR}=4.682)$. Therefore, when a patient is diagnosed with SRCC, postoperative drug therapy may extend the patient's survival time to a certain extent. In addition, judging the proportion of sarcomatoid components on time may provide a certain reference to understanding the patient's condition.

Ultimately, the present study has identified that postoperative drug treatment and sarcoma elements were protective and risk factors for SRCC. However, due to the fact that SRCC is rare in clinical practice, the present research was not able to further analyze the effects of different drugs on the survival of patients with SRCC.

To the best of our knowledge, until now, there has not been any research analyzing the survival time of patients with SRCC.

\section{Acknowledgements}

Not applicable.

\section{Funding}

No funding was received.

\section{Availability of data and materials}

The datasets used and/or analyzed during the present study are available from the corresponding author on reasonable request.

\section{Authors' contributions}

YW collected clinical data and wrote the manuscript. WS designed and supervised the current study. KY, XT, MX and HY collected and interpreted clinical data. All authors read and approved the final version of the manuscript.

\section{Ethics approval and consent to participate}

The present study was performed in accordance with the ethical standards of the Institutional Review Board of the First Hospital of Shanxi Medical University (approval no. 2018-K006), in addition to the 1964 Helsinki declaration and its later amendments or comparable ethical standards. The Institutional Review Board of the First Hospital of Shanxi Medical University waived the requirement for informed consent due to the retrospective design of this study.

\section{Patient consent for publication}

All patients provided their consent for publication.

\section{Competing interests}

The authors declare that they have no competing interests.

\section{References}

1. Siegel RL, Miller KD and Jemal A: Cancer statistics 2019. CA Cancer J Clin 69: 7-34, 2019.

2. Dingwei YE and Zhang H: Current status and development trend of renal cancer diagnosis and treatment in China. Chine J Urol 35: 401-405, 2014 (In Chinese).

3. Xian WEI, Xinwen KE, Zhiquan HU, et al: Clinical efficacy and safety of sunitinib in the treatment of advanced renal cell carcinoma. J Mod Reprod Oncol 9: 133-136, 2017 (In Chinese).

4. Shuang WB, Zhang YH and Tong XN: Recent researches on sarcomatoid renal cell carcinoma. E J Transl Med 2: 6-8, 2018 (In Chinese).

5. Zhang L, Wu B, Zha Z, Zhao H and Feng Y: The prognostic value and clinicopathological features of sarcomatoid differentiation in patients with renal cell carcinoma: A systematic review and meta-analysis. Cancer Manag Res 10: 1687-1703, 2018.

6. Zhang BY, Thompson RH, Lohse CM, Leibovich BC, Boorjian SA, Cheville JC and Costello BA: A novel prognostic model for patients with sarcomatoid renal cell carcinoma. BJU Int 115: 405-411, 2015.

7. He $\mathrm{H}$ and Magi-Galluzzi C: Epithelial-to-mesenchymal transition in renal neoplasms. Adv Anat Pathol 21: 174-180, 2014.

8. Kyriakopoulos CE, Chittoria N, Choueiri TK, Kroeger N, Lee JL, Srinivas S, Knox JJ, Bjarnason GA, Ernst SD, Wood LA, et al: Outcome of patients with metastatic sarcomatoid renal cell carcinoma: Results from the international metastatic renal cell carcinoma database consortium. Clin Genitourin Cancer 13: e79-e85, 2015.

9. Lebacle C, Pooli A, Bessede T, Irani J, Pantuck AJ and Drakaki A: Epidemiology, biology and treatment of sarcomatoid RCC: Current state of the art. World J Urol 37: 115-123, 2019.

10. Appleman LJ and Marachie JK: Systemic therapy following metastasectomy for renal cell carcinoma: Using insights from other clinical settings to address unanswered questions. Urol Oncol 36: 17-22, 2018.

11. Nanus DM, GarinoA, Milowsky MI, Larkin M and Dutcher JP: Active chemotherapy for sarcomatoid and rapidly progressing renal cell carcinoma. Cancer 101: 1545-1551, 2004.

12. Rashid MH, Welsh CT, Bissada NK and Chaudhary UB: Complete response to adriamycin and ifosfamide in a patient with sarcomatoid renal cell carcinoma. Am J Clin Oncol 28: 107-108, 2005.

13. Keskin SK, Msaouel P, Hess KR, Yu KJ, Matin SF, Sircar K, Tamboli P, Jonasch E, Wood CG, Karam JA and Tannir NM: Outcomes of patients with renal cell carcinoma and sarcomatoid dedifferentiation treated with nephrectomy and systemic therapies: Comparison between the cytokine and targeted therapy eras. J Urol 198: 530-537, 2017.

14. Shuch B, Bratslavsky G, Shih J, Vourganti S, Finley D, Castor B, Treat E, Linehan WM, Pantuck AJ, Said JW and Belldegrun AS: Impact of pathological tumour characteristics in patients with sarcomatoid renal cell carcinoma. BJU Int 109: 1600-1606, 2012.

15. Kim T, Zargar-Shoshtari K, Dhillon J, Lin HY, Yue B, Fishman M, Sverrisson EF, Spiess PE, Gupta S, Poch MA and Sexton WJ: Using percentage of sarcomatoid differentiation as a prognostic factor in renal cell carcinoma. Clin Genitourin Cancer 13: 225-230, 2015

16. Chen JH,Liu XD and Yang LI: Sarcomatoid renal cell carcinoma: One case report. J Kun Ming Med Univ 29: 483-484, 2007.

17. Pei XK, Jiang W, Yang SB, Yang QS and Long W: A case of ipsilateral renal sarcomatoid renal cell carcinoma with angiomyolipoma at the same time and literature review. J Contemp Urol Reproduct Oncol: 304-305, 2014

18. Yin MX, Zhang Y, Ye XQ, Lin B and Xiao C: Sarcomatoid renal cell carcinoma: Two case reports. Chin J Clin Exp Pathol 26: 767-768, 2010 (In Chinese).

19. Li L and Zhou GY: Sarcomatoid renal cell carcinoma: Two case reports. Chin J Clin Exp Pathol 20: 384, 2004 (In Chinese). 
20. Hu YC, Huang XY, Li D, Leng J, Bo JJ and Wang YX: Sarcomatoid renal cell carcinoma: One case report. Chin $\mathrm{J}$ Urol 23: 217, 2002 (In Chinese).

21. Komeya M, Sano F, Kagota M, Murakami T, Makiyama K, Miyoshi Y, Nakaigawa N, Ogawa T, Uemura H, Yao M, et al: Case of sarcomatoid renal cell carcinoma developed in the chalked kidney (putty kidney). Hinyokika Kiyo 55: 253-257, 2009 (In Japanese).

22. Ni XH, Yu GH, Ruan ZY, Lin J and Cai FB: Sarcomatoid renal cell carcinoma: Three cases report. Chin J Urol 21: 506-507, 2000 (In Chinese).

23. Gao Y, Shuang WB, Tong XN, Li S and Zhang YH: Bilateral sarcomatoid renal cell carcinoma: An uncommon case in young femal patient. Transl Surg 2: 74-77, 2017.

24. Takada T, Kinouchi T, Kinoshita T, Hatano K, Kobayashi M, Inoue H, Hara T and Yamaguchi S: Four cases of sarcomatoid renal cell carcinoma. Hinyokika Kiy 55: 93-97, 2009 (In Japanese).

25. Tsuchiyama $\mathrm{K}$, Ito $\mathrm{H}$, Ishida $\mathrm{H}$, Itoh $\mathrm{H}$ and Yokoyama $\mathrm{O}$ : Advanced sarcomatoid renal cell carcinoma effectively treated with sunitinib: Report of a case. Hinyokika Kiy 57: 615-618, 2011.

26. Minagawa T, Nishizawa S, Kamigaito M, Nakayama $T$ and Okaneya T: Sarcomatoid renal cell carcinoma with von Hippel-Lindau disease: A case report. Nihon Hinyokika Gakkai Zasshi 98: 723-726, 2007 (In Japanese).

27. Kwak C, Park YH, Jeong CW, Jeong H, Lee SE, Moon KC and $\mathrm{Ku} \mathrm{JH}$ : Sarcomatoid differentiation as a prognostic factor for immunotherapy in metastatic renal cell carcinoma. J Surg Oncol 95: 317-323, 2007.

28. Cangiano T, Liao J, Naitoh J, Dorey F, Figlin R and Belldegrun A: Sarcomatoid renal cell carcinoma: Biologic behavior, prognosis, and response to combined surgical resection and immunotherapy. J Clin Oncol 17: 523-528, 1999.

29. Stadler WM, Huo D, George C, Yang X, Ryan CW, Karrison T, Zimmerman TM and Vogelzang NJ: Prognostic factors for survival with gemcitabine plus 5-fluorouracil based regimens for metastatic renal cancer. J Urol 170: 1141-1145, 2003.
30. Motzer RJ and Russo P: Systemic therapy for renal cell carcinoma. J Urol 163: 408-417, 2000.

31. Motzer RJ, Rini BI, Bukowski RM, Curti BD, George DJ, Hudes GR, Redman BG, Margolin KA, Merchan JR, Wilding G, et al: Sunitinib in patients with metastatic renal cell carcinoma. JAMA 295: 2516-2624, 2006.

32. Dodd PM, McCaffrey JA, Hilton S, Mazumdar M, Herr H, Kelly WK, Icasiano E, Boyle MG and Bajorin DF: Phase I evaluation of sequential doxorubicin gemcitabine then ifosfamide paclitaxel cisplatin for patients with unresectable or metastatic transitional-cell carcinoma of the urothelial tract. J Clin Oncol 18: 840-846, 2000.

33. Bono AV and Lovisolo JA: Renal cell carcinoma-diagnosis and treatment: State of the art. Eur Urol 31 (Suppl 1): S47-S55, 1997.

34. Zhang L, Shi HY and Hong BF: The clinicopathological analysis of 16 cases of sarcomatoid renal cell carcinoma. Med J Chin PLA: 356-358, 2006.

35. Grabowski M, Huzarski T, Lubinski J and Sikorski A: Survival in patients with rare subtypes of renal cell carcinoma. BJU Int 89: 599-600, 2002.

36. Leibovich BC, Han KR, Bui MH, Pantuck AJ, Dorey FJ, Figlin RA and Belldegrun A: Scoring algorithm to predict survival after nephrectomy and immunotherapy in patients with metastatic renal cell carcinoma: A stratification tool for prospective clinical trials. Cancer 98: 2566-2575, 2003.

37. Escudier B, Szczylik C, Eisen T, Stadler WM, Schwartz B and Bukowski MSM: Randomized phase III trial of the Raf kinase and VEGFR inhibitor sorafenib (BAY 43-9006) in patients with advanced renal cell carcinoma (RCC). J Clin Oncol 23: 4510, 2005.

38. Culine S, Bkradda M, Terrier-Lacombe MJ and Droz JP: Treatment of sarcomatoid renal cell carcinoma: Is there a role for chemotherapy? Eur Urol 27: 138-141, 1995. 